\title{
A CADAVERIC STUDY OF COMMMON PERONEAL NERVE IN RELATION TO FIBULAR TUNNEL
}

KEY WORDS:

Jaskaran Singh

Assistant Professor, Department Of Anatomy, S P Medical College, Bikaner, Rajasthan.

\section{Bhawani Shankar Modi}

\section{Kavita Pahuja}

\section{Tejendra Singh*}

\section{Assistant Professor, Department Of Anatomy, F H Medical College, Agra, UP.}

Professor, Department Of Anatomy, S P Medical College, Bikaner, Rajasthan Associate Professor, Department Of Anatomy, F H Medical College, Agra, Up. *Corresponding Author

INTRODUCTION: The common peroneal nerve is major lateral division of the sciatic nerve supplies lateral and anterior compartment of leg, when injured may leads to debilitating conditions such as foot drop and sensory loss or numbness in its supplied area. Common peroneal nerve's position subjects it to nerve injuries at two places one behind the knee joint where the nerve is superficial and other being the course of nerve through the fibular tunnel where its being tugged between musculo-aponeurotic fibers of peroneus longus muscle. Nerve injuries to common peroneal nerve has been attributed to several factors depending upon its anatomical position such as this may be due to sudden weight loss, prolonged sitting in squatting position, meniscus injuries in athletes or whether it is any surgical procedures involving the upper part of tibia and fibula.

MATERIAL \& METHODS: In present study we examine 70 lower limbs equally of right and left sides, the course, branching pattern and other reference point distances were measured with the help of metallic scale and dissections were photograph.

RESULT: In $60 \%$ cases nerve separate from sciatic at the apex of popliteal fossa and in $80 \%$ cases it passes through the groove and then in about $70 \%$ specimen it passes through fibular tunnel, where it remains on an average $1.33 \mathrm{~cm}$ below the fibular head. The average distance of the nerve division was found $2.73 \mathrm{~cm}$ and just below that at a distance of $4.29 \mathrm{~cm}$ the nerve is in close contact with the bone.

CONCLUSION: In present study we have observed average 7 muscular branches with variable origin from the common peroneal nerve in fibular tunnel which are likely to be damaged during surgical incision at this site.

\section{INTRODUCTION}

The Common peroneal nerve (CPN) has several unique anatomical features such as its separation from sciatic nerve which is highly variable and range from the gluteal region to the popliteal fossa, with this the covering of sciatic nerve and its two component nerves tibial and common peroneal nerve also have their separate fascial sheath, then the lower course of common peroneal nerve along the biceps femoris muscle, particularly the groove between biceps femoris and the lateral head of gastrocnemius, where this is subcutaneous can be palpated and thus making it susceptible to compression and injuries at this site, not only here but when the nerve descends down and winds round the neck of fibula, usually it runs as a single trunk but its relationship to the bone and the muscle covering it is crucial and of special concern. Variant of the course of common peroneal nerve along the distal biceps femoris muscle has been reported. A tunnel can be formed between the biceps femoris muscle and the lateral gastrocnemius muscle then also in a previous study reported the five cases of compression of the common fibular nerve at the fibular tunnel secondary to sciatic nerve injury ${ }^{1}$.

Three fibrous band for the formation of fibular tunnel has been reported as, 1) Fibrous band deep to the superficial head of the peroneus longus, 2) Fibrous band on the surface of the deep head of the peroneus longus, 3) Confluence of the origins of the soleus muscle and the peroneus longus. Knowledge of all three of these potential sources allows the surgeon to diagnose and sequentially release systematically all possible sites of compression.

Prolonged working in sitting position has been associated with compression of common peroneal nerve because it leads to hyper-flexed position of knee joint ${ }^{3}$. Some other studies $^{4-5}$ have reported more proximal bifurcation of the peroneal nerve found in $10 \%$ of preserved specimens and makes the peroneal nerve more prone to injury with |www.worldwidejournals.com arthroscopic inside-out lateral meniscal repair. The entrapment or impingement of common peroneal nerve in fibular tunnel occurs mainly between the fibers of the peroneus longus and the fibular neck and is typically exacerbated by forced inversion of the foot, stretching the peroneal nerve. ${ }^{6}$ It was noted that $20 \%$ of fibular mononeuropathy were associated with loss of subcutaneous fat and subsequent compression of common peroneal nerve ${ }^{7}$.

Even in other surgical procedures at the knee joint the damage to the common peroneal nerve has been documented such as in intra medullary nailing of tibial and fibular fractures ${ }^{8,9}$. Exact location of common peroneal nerve in relation to fibula is very important to perform surgical procedures at this level; same is reported in a study ${ }^{10}$ of high tibial osteotomies, done in association with fibular osteotomies where it was found that fibular nerve abnormalities comprise about $2 \%-27 \%$ of total cases. The presence of the fibular tunnel firmly being documented in previous studies ${ }^{11}$ and linked to the compression injuries, as it has been reported that the osteo-fibrous tunnel between the peroneus longus muscle and the fibula can be tightened by an ossification at the peroneus longus muscle origin called as tug lesion which commonly occur on the lateral side of the fibula, while a soleus tug lesion occurs on the medial side.

As far as the matter of limited subjects concerned, these are dissection studies and this can be understand from this fact for about the less availability of subjects, so the present study could also be seen as extension of the data on this subject.

\section{MATERIAL \& METHODS}

This study is a observational dissection study which is conducted in a period from August 2017 to April 2021, a total number of 35 formaldehyde embalmed cadavers of unknown age were selected for study from the Department of Anatomy, S P Medical College, Bikaner and F.H. Medical College, Agra. Total 70 Lower limbs (35 from right side and 35 from left side) 
were dissected during routine undergraduate dissection. The skin and superficial fascia on the lateral and posterior aspects of the limbs was raised from the underlying deep fascia from the junction of the middle and lower thirds of the thigh to the level of the junction of upper third and the middle third of the $\mathrm{leg}^{14}$. After removal of the deep fascia, the contents of the popliteal fossa were cleared. The position of the nerves as it course downward along the lateral boundaries of popliteal fossa varies as it may pass through the groove or below the groove over the fibers of gastrocnemius muscle. The tendon of biceps femoris was then detached from the fibular head and the aponeurotic extension from it onto the lateral surface of peroneus longus muscle incised longitudinally at its attachment with the upper part of the anterior inter-muscular septum. The upper segment of the peroneus longus muscle was reflected upwards to expose the course and branches of the main trunk. (Figure 1)

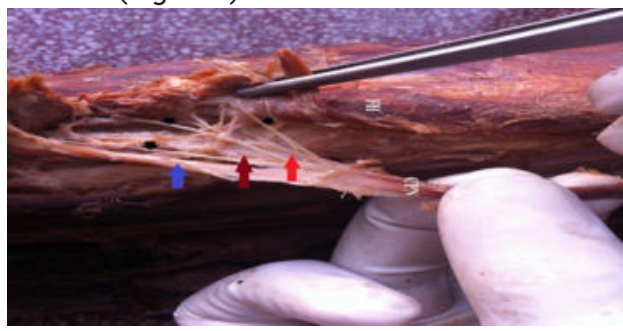

Figure 1 showing early division of Common peroneal nerve (CPN) FH- Fibular head, Black arrows-Muscular branches, Red arrow-Articular branch, Brown arrow-Deep peroneal nerve, Blue arrow-Superficial peroneal nerve

The further course of the nerve traced between the peroneous longus and extensor digitorum longus muscles. By removing upper segment of the peroneus longus muscle most prominent point on the postero-lateral aspect of the head of the fibula was exposed and cleaned of for the reference point. Reference point:- Most prominent point on the postero-lateral aspect of the head of the fibula. Fibular tunnel:- Musculoaponeurotic fibrous tunnel deep to the upper most origin of peroneus longus muscle from the neck of fibula. Points of concern were marked with the help of pins and then measured with the help of metallic scale calibrated to measure tenth of centimeter (Figure 2).

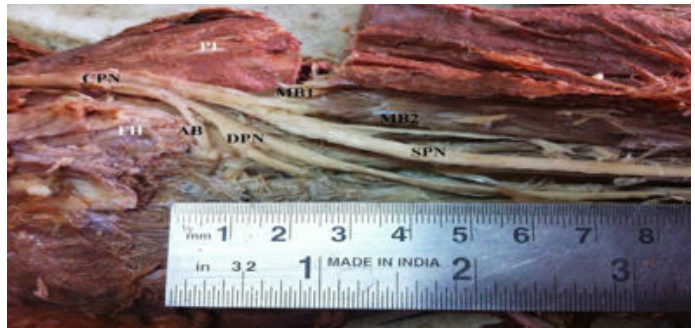

FIGURE 2 SHOWING BRANCHING OF COMMON PERONEAL NERVE (CPN) IN FIBULAR TUNNEL FHFIBULAR HEAD, MB1 \& MB2-Muscular branches ABArticular branch, DPN-Deep peroneal nerve, SPN Superficial peroneal nerve, PL-Peroneus longus muscle

Each parameter was measured thrice and the mean was taken as final reading. Non metric parameters were observed and the dissection was photographed. The following observations were made.

1.The origin point of the common peroneal nerve.

2.The position of the common peroneal nerve (a. In the groove between the biceps femoris insertion and the lateral head of the gastrocnemius, b. over the insertion of biceps femoris, c. over the lateral head of gastrocnemius.)

3. Course and branching pattern of common peroneal nerve. 4.The distance of the common peroneal nerve as it crosses the lateral aspect of the neck of fibula to be measured.

5. The distance from the reference point (head of fibula) to the origin of the branches of the common peroneal nerve and its two main divisions will be measured.

\section{Statistical methods:-}

All the measurements were taken in centimeters. Frequencies, Mean, Standard Deviations and Percentage were calculated for metric and non-metric parameters by applying standard formula for this.

\section{RESULTS}

For 70 lower limbs (35 right and 35 left) non metric and metric parameters were recorded.

The non-metric parameters were tabulated and presented in Table 1 .

\begin{tabular}{|c|c|c|c|c|}
\hline \multirow{2}{*}{\multicolumn{2}{|c|}{\begin{tabular}{|c|} 
TABLE I DISTRIBUTION OF CASES FOF \\
VARIABLES ACCORDING TO SIDE OF LIM \\
Parameters
\end{tabular}}} & & & \\
\hline & & \multicolumn{3}{|c|}{\begin{tabular}{|l|l|l|} 
Right & Left & Total \\
side & side
\end{tabular}} \\
\hline \multirow{2}{*}{$\begin{array}{l}\text { Division site of CPN in poplitel } \\
\text { fossa }\end{array}$} & Apex & 21 & 21 & 42 \\
\hline & Middle & 14 & 14 & 28 \\
\hline \multirow[t]{2}{*}{ Position of CPN } & Groove & 28 & 28 & 56 \\
\hline & Below & 7 & 7 & 14 \\
\hline \multirow{2}{*}{$\begin{array}{l}\text { Branching of CPN in refernce to } \\
\text { fibular tunnel }\end{array}$} & Proximal & 17 & 18 & 35 \\
\hline & Distal & 17 & 18 & 35 \\
\hline \multirow[t]{2}{*}{ Presence of Fibrous band } & Present & 28 & 21 & 49 \\
\hline & Absent & 7 & 14 & 21 \\
\hline CPN- Commor & & & & \\
\hline
\end{tabular}

For the metric parameters Mean values, Standard deviation and Range are shown in table 2.

\begin{tabular}{|c|c|c|c|c|c|c|c|c|c|c|c|c|}
\hline ABLE 2 I & IEAN V. & UES A & ND RANG & E OF VARI & IOUS DI & STANCE & MEASUR & ED. & & & & \\
\hline Parameters & Right Sic & & & & Left Side & & & & Total & & & \\
\hline & \begin{tabular}{|l|} 
Mean \\
\end{tabular} & SD & \begin{tabular}{|l|} 
Minimum \\
\end{tabular} & Maximum & Mean & SD & Minimum & Maximum & Mean & SD & Minimum & Maximum \\
\hline $\begin{array}{l}\text { Length of } \\
\text { CPN }\end{array}$ & 11.0400 & 2.47620 & 8.00 & 15.00 & 11.5900 & 2.67310 & 8.10 & 16.00 & 11.3150 & 2.52363 & 8.00 & 16.00 \\
\hline $\begin{array}{l}\text { Distance of } \\
\text { fibular } \\
\text { tunnel } \\
\text { from HOF }\end{array}$ & 1.3650 & .53232 & .80 & 2.30 & 1.3000 & .61146 & .50 & 2.30 & 1.3325 & .55896 & .50 & 2.30 \\
\hline $\begin{array}{l}\text { Distance of } \\
\text { articular } \\
\text { branch } \\
\text { from HOF }\end{array}$ & 1.3600 & .63631 & .60 & 2.70 & 1.1500 & .83699 & .00 & 2.30 & 1.2550 & .73160 & .00 & 2.70 \\
\hline \begin{tabular}{|l|} 
Articular \\
branch \\
bone \\
contact point \\
distance \\
from HOF
\end{tabular} & 1.7000 & .60736 & 1.00 & 2.90 & 1.5450 & .63616 & .70 & 2.40 & 1.6225 & .61054 & .70 & 2.90 \\
\hline
\end{tabular}




\begin{tabular}{|l|l|l|l|l|l|l|l|l|l|l|l|l|}
\hline $\begin{array}{l}\text { Distance } \\
\text { first } \\
\text { muscular } \\
\text { branch } \\
\text { from HOF }\end{array}$ & 1.7500 & .72303 & .80 & 3.10 & 1.9300 & .72426 & 1.00 & 3.20 & 1.8400 & .71037 & .80 & 3.20 \\
\hline $\begin{array}{l}\text { Branching } \\
\text { point } \\
\text { distance of } \\
\text { CPN from } \\
\text { HOF }\end{array}$ & 2.6400 & 1.25007 & 1.10 & 4.40 & 2.8300 & 1.35405 & .00 & 4.50 & 2.7350 & 1.27208 .00 & 4.50 \\
\hline $\begin{array}{l}\text { Bone } \\
\text { contact } \\
\text { point } \\
\text { distance of } \\
\begin{array}{l}\text { CPN from } \\
\text { HOF }\end{array}\end{array}$ \\
\hline \begin{tabular}{l} 
CPN- Common peroneal nerve, HOF- Head of fibula. All values are in centimeters. \\
\hline
\end{tabular}
\end{tabular}

We found origin of common peroneal nerve at apex of popliteal fossa in 42 limbs. The divisions of sciatic nerve at middle level were found in 28 limbs. We did not found separation of common peroneal nerve at lower level.

The position of the common peroneal nerve observed in 28 limbs in the groove equally for right and left sides and in 7 limbs below the groove equally in both right and left side. Branching pattern of common peroneal nerve examined as the nerve enters into the fibular tunnel. It may enter the tunnel as a single trunk and then branch or may give branches before the tunnel. Common peroneal nerve shows equal distribution for its branching pattern in both groups (branching before and inside the tunnel) as well as both sides. The presence of musculo-aponeuratic fibrous band was examined and it was found in 28 right limbs and in 21 left limbs and found absent in 7 right limbs and in 14 left limbs. Out of total 70 limbs $70 \%$ specimen shows the presence of fibrous band.

The mean length of common peroneal nerve was found $11.04 \pm 2.47 \mathrm{~cm}$ in right side and $11.59 \pm 2.67 \mathrm{~cm}$ in left side. Mean common peroneal nerve length of pooled data was found $11.31 \pm 2.52 \mathrm{~cm}$. The range of the common peroneal nerve length is shown in Table No. 1. The mean distance from head of fibula to fibular tunnel was found $1.36 \pm 0.53 \mathrm{~cm}$ in right side, $1.30 \pm 0.61 \mathrm{~cm}$ in left side and $1.33 \pm 0.55 \mathrm{~cm}$ in total number of samples. The mean distance of origin of articular branch was observed $1.36 \pm 0.63 \mathrm{~cm}$ in right side, $1.15 \pm 0.83$ $\mathrm{cm}$ in left side and $1.25 \pm 0.73 \mathrm{~cm}$ in total number of samples. The mean distance for bone contact point of articular branch seen as $1.70 \pm 0.60 \mathrm{~cm}$ in right side, $1.54 \pm 0.63 \mathrm{~cm}$ in left side and $1.62 \pm 0.61 \mathrm{~cm}$ in total number of samples.

The median value for total number of muscular branches recorded as 7 in total number of samples. The mean distance of origin of first muscular branch was observed $1.75 \pm 0.72 \mathrm{~cm}$ in right side, $1.93 \pm 0.72 \mathrm{~cm}$ in left side and $1.84 \pm 0.71 \mathrm{~cm}$ in pooled samples. The mean distance of branching point of common peroneal nerve was calculated as $2.64 \pm 1.25 \mathrm{~cm}$ in right side, $2.83 \pm 1.35 \mathrm{~cm}$ in left side and $2.73 \pm 1.27 \mathrm{~cm}$ in pooled samples. The mean distance for bone contact point of common peroneal nerve was observed as $3.99 \pm 1.40 \mathrm{~cm}$ in right side, $4.59 \pm 1.33 \mathrm{~cm}$ in left side and $4.29 \pm 1.36 \mathrm{~cm}$ in total number of samples.

\section{DISCUSSION}

We have observed the origin of common peroneal nerve in reference to its separation from sciatic nerve as whether it divides, at the apex of the popliteal fossa, middle of it or at the lower level of it, because this is relevant to the lower position of the common peroneal nerve in the groove found between biceps femoris and lateral head of gastrocnimeus, which is the site where the nerve lies subcutaneous and only protected through a thick fatty sheath. Out of total 70 limbs, we found origin of common peroneal nerve at apex in 42 limbs and at middle level in 28
limbs.In most common pattern of Sciatic nerve it passes out through greater sciatic foramen below piriformis and divides at the apex of the popliteal fossa $(85-89 \%)^{15}$.

As the nerve enters the fibular tunnel deep to the muscle fibers of peroneus longus muscle the mean distance of the entry point from head of fibula was found $1.33 \pm 0.55 \mathrm{~cm}$. This is useful in deciding site of incision for decompression of the nerve at this location as this is also advised by previously to make a 3 to $5 \mathrm{~cm}$ oblique incision parallel to the course of the nerve over the neck of the fibula posterior to the lateral compartment ${ }^{12,13}$.

In our observations common peroneal nerve shows equal distribution for its branching pattern in both groups (branching before and inside the tunnel) as well as both sides. It may enter the tunnel as a single trunk and then branch or may give branches before the tunnel. In typical pattern the first branch to observe is articular branch after which nerve divided into its two main divisions, however the branching pattern is variable, the mean distance of articular branch from the head of fibula was measured as $1.25 \pm 0.73 \mathrm{~cm}$ which is less than previously reported ${ }^{6}$, though not directly but the distance from head to the fibular tunnel. As we seen the nerve may branch before the tunnel so the less distance of articular branch from head can be understand as an important fact for surgical procedures. Articular branch through its course becomes almost horizontal posterior to the neck of fibula at this level the nerve was closely applied to the bone hence the bone contact point of articular branch was measured to calculate the mean distance from head of fibula, the mean distance was found as $1.62 \mathrm{~cm}$.

\section{CONCLUSION:}

In the present study this has been observed that common peroneal nerve most commonly separates from sciatic nerve near the apex of popliteal fossa and it descends along the medial border of biceps femoris muscle where a groove is formed and in most of cases nerve run through the groove being superficial and only protected by a subcutaneous fatty sheath. The presence of the fibular tunnel is invariably accepted and its role in compression. injuries undoubtedly attributed to tug lesions deep to peroneus longus muscle. The presence of fibular tunnel has also been confirmed in the present study. The branching pattern of common peroneal nerve is not so variable and the nerve takes almost constant course in relation to neck of fibula however its distances from fibular head as we found $4.29 \mathrm{~cm}$ where it comes in contact with bone and $2.73 \mathrm{~cm}$ where it branches are slightly higher as compare to previous studies thus the measurements can be used as reference point for studied region while performing surgical procedures. Our findings with slight deviation otherwise coincided with the previously reported works, only being extended to some level as we found average seven muscular branches at this level and position of articular branch assessed. More work on a larger sample size is 
required to access the position and number of muscular branches in fibular tunnel from common peroneal nerve as we have observed more variations on this part of the nerve.

\section{REFERENCES}

1. WANG YZ, MA GW, LIU QM (2002) Treatment of common fibular nerve secondary compression syndrome. Zhongguo Xiu Fu Chong Jian Wai KeZa Zhi, May; 16(Pt3): 166-7.

2. DELLON AL, EBMER J, SWIER P (2002) Anatomic variations related to decompression of the common peroneal nerve at the fibular head. Ann Plast Surg, 48:30-34.

3. SANDHU HS, SANDHEY BS (1976) Occuptional compression of the common peroneal nerve at the neck of the fibula. Aust N ZJ Surg, May; 46(Pt 2): 160-3.

4. JURIST KA, GREENE PW 3rd, SHIRKHODA A (1989) Peroneal nerve dysfunction as a complication of lateral meniscus repair: a case report and anatomic dissection. Arthroscopy, 5(Pt 2): 141-147.

5. DEUTSCH A, WYZYKOWSKI RJ, VICTOROFF BN (1999) Evaluation of the anatomy of the common peroneal nerve. Defining nerve-at-risk in arthroscopically assisted lateral meniscus repair. Am J Sports Med, 27(Pt 1):10-15.

6. RYANW, MAHONY N,DELANEY M, O'BRIEN M,MURRAY P (2003) Relationship of the common peroneal nerve and its branches to the head and neck of the fibula. Clin Anat, 16 (Pt 6):501-505.

7. CRUZ-MARTINEZ A, ARPA J, PALAU F (2000) Peroneal neuropathy after weight loss.J Peripher Nerv Syst, 5:101-5.

8. SATKU K, WEE JT, KUMAR VP, ONG B, PHO RW (1992) The dropped big toe. Ann Acad Med Singapore, 21:222-5.

9. ROBINSON CM, O'DONNELLJ,WILL E, KEATING JF (1999) Dropped hallux after the intramedullary nailing of tibial fractures.J Bone Joint $\mathrm{Surg} B r, 81: 481-4$.

10. AYDOGDU S, CULLU E, ARAC N (2000) Prolonged peroneal nerve dysfunction after high tibial osteotomy: pre- and postoperative electrophysiological study. Knee Surg Sports Traumatol Arthrosc, 8:305-8.

11. TEHRANZADEH J (1987) The spectrum of avulsion and avulsion-likeinjuries of the musculoskeletal system. Radiographics, $7(\mathrm{Pt} 5): 945-74$.

12. PALEY D (2005) Principles of Deformity Correction. 1st ed, Corr. 3rd 15 printing.Reved.Berlin, Springer-Verlag, 19.

13. NOGUEIRA MP, PEREIRA CAM, HERNANDEZ AJ (2003) Biomechanical Study of the Tension of the Fibular Nerve and the Importance of Its Surgical Decompression in Lower Limb Deformity Correction-A Cadaver Study. Limb Lengthening and Reconstruction Society Association for the Study and Application of the Methods of Ilizarov North America. The Fairmont Coply Plaza Hotel. Boston, MA, USA.

14. ROMANES GJ (1997) Cunningham's Manual of Practical Anatomy. 15th ed., Mass Publishing Co. Egypt, 1:160,188.

15. STANDRING S (2005) Gray's Anatomy 39th Edition: The Anatomical Basis of Clinical Practice. AJNR, 26:2703-2704. 